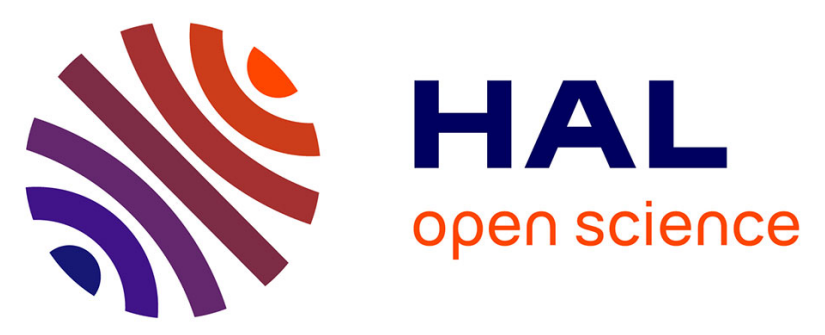

\title{
Effects of magnetic core geometry on false detection in residual current sensor
}

\author{
Bruno Colin, Christian Chillet, Afef Kedous-Lebouc, Patrick Mas
}

\section{To cite this version:}

Bruno Colin, Christian Chillet, Afef Kedous-Lebouc, Patrick Mas. Effects of magnetic core geometry on false detection in residual current sensor. Journal of Magnetism and Magnetic Materials, 2006, pp.804-806. 10.1016/j.jmmm.2006.02.273 . hal-00192256

\section{HAL Id: hal-00192256 https://hal.science/hal-00192256}

Submitted on 14 Jan 2020

HAL is a multi-disciplinary open access archive for the deposit and dissemination of scientific research documents, whether they are published or not. The documents may come from teaching and research institutions in France or abroad, or from public or private research centers.
L'archive ouverte pluridisciplinaire HAL, est destinée au dépôt et à la diffusion de documents scientifiques de niveau recherche, publiés ou non, émanant des établissements d'enseignement et de recherche français ou étrangers, des laboratoires publics ou privés. 


\title{
Effects of magnetic core geometry on false detection in residual current sensor
}

\author{
Bruno Colin $^{\mathrm{a}, \mathrm{b}, *}$, Christian Chillet ${ }^{\mathrm{a}}$, Afef Kedous-Lebouc ${ }^{\mathrm{a}}$, Patrick Mas ${ }^{\mathrm{b}}$

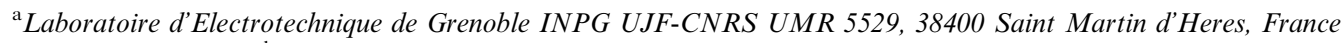 \\ ${ }^{\mathrm{b}}$ Schneider-Electric, Rue Pierre Mendès France, 38320 Eybens, France
}

\begin{abstract}
Under high-supply current, residual circuit breakers are subject to abnormal tripping, caused by false residual currents. Geometric or magnetic anomalies in the circuit breaker ring core seem to be responsible for these abnormal currents. This paper studies a few anomalies (spiral shape effect, conductor eccentricity, lamination effect) and calculates different contributions using the finite element simulations. The results show that the ring core, made of thin wound magnetic tape, is particularly sensitive to primary conductor eccentricity.
\end{abstract}

PACS: $85-70$ Ay

Keywords: Differential circuit breaker; Ring core; Nuisance tripping

\section{Introduction}

Residual current device must ensure the users safety against electrical shocks without disturbing normal operations of electrical installations. It must detect residual current in the installation supply and trigger the opening of the installation circuit breaker when this current exceeds a given threshold (typically $30 \mathrm{~mA}$ ). It is composed of:

- A $40 \mathrm{~mm}$ wide, $1.5 \mathrm{~mm}$ thick, $10 \mathrm{~mm}$ high magnetic core of a high-permeability material which surrounds the supply conductors.

- A short circuited secondary coil wound around the core which picks up the flux created by the conductors.

In theory, the device works as a current transformer and should detect only residual current in the primary conductors. In practice, even under normal conditions, a false residual current (FRC) is measured and leads to abnormal tripping. The current standards [1] impose the

\footnotetext{
*Corresponding author. Laboratoire d'Electrotechnique de Grenoble INPG UJF-CNRS UMR 5529, 38400 Saint Martin d'Heres, France.

E-mail address: bruno.colin@leg.ensieg.inpg.fr (B. Colin).
}

circuit breakers to be immune to the nuisance tripping under six times the nominal current (several hundreds Amperes). To achieve that, partial solutions, like external shielding or compensation coils, are used today [2].

This paper is focused on the different sources of FRCs using the finite element simulations and more specifically on the analysis of the effect of the shape of magnetic ring core and on the impact of the conductor eccentricity. The impact of a non-uniform secondary winding will not be studied here, even though experimental data show a significant contribution to FRCs.

The ring core is made of a wound thin high permeability magnetic ribbon. The ribbon ends, placed inside and outside the core, create an asymmetry in the core which generates FRCs in the secondary winding (the spiral shape effect). Moreover, the thin layers of air gaps between layers of the core cause a shielding phenomenon and concentrate the flux to the first layers of the core, which are oversaturated.

\section{Simulation conditions}

To study the effect of the magnetic ring core separately, the finite element simulations have been carried out (Flux 


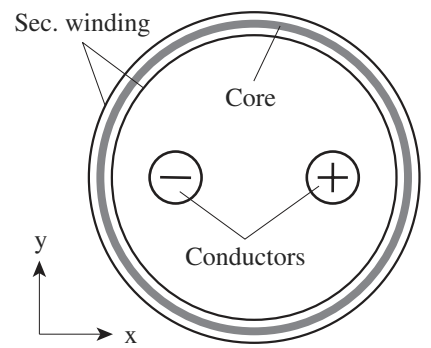

Fig. 1. Simulated model.

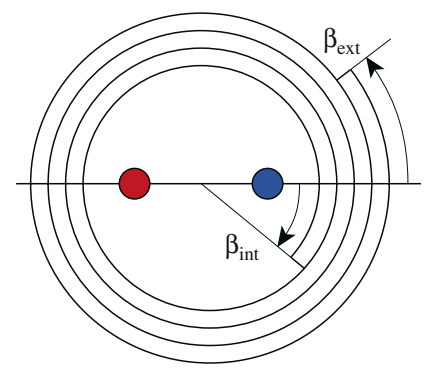

Fig. 2. Angular position of ends.

software). To simplify the problem and to avoid the edge effects a two-dimensional single phase residual circuit device was modelled (Fig. 1).

Simulations have been achieved under a step-by-step time mode, using sinusoidal current sources and the following conditions:

- The secondary winding is modelled by two current layers placed inside and outside of the core. An electrical circuit coupled with the model connects the two coils with a $26 \Omega$ resistance.

- The magnetic core is modelled either as a wound spiral or as an assembly of concentric layers. The number of magnetic layers is variable, core and air layer thickness remaining constant, 30 by default. The magnetic material uses an isotropic non-linear $B(H)$ law. The air layers in the magnetic core are represented by a linear region with vacuum magnetic properties.

- For a spiral shape core, the angular positions of two ends are defined by $\beta_{\text {int }}$ and $\beta_{\text {ext }}$ (Fig. 2).

\section{Results and discussion}

Fig. 3 shows the effect of the spiral shape. Indeed, to avoid the ribbon end, the ribbon first layer flux gradually goes through the second layer. This leads to an asymmetrical saturation of the second layer, which causes FRCs.

The impact of the ribbon extremities decreases with the layer thickness. Indeed, a core composed from an infinite number of layers should tend towards an ideal ring. This has been confirmed by simulation.

This asymmetrical effect is more or less important and depends on the ribbon extremities position. Figs. 4 and 5

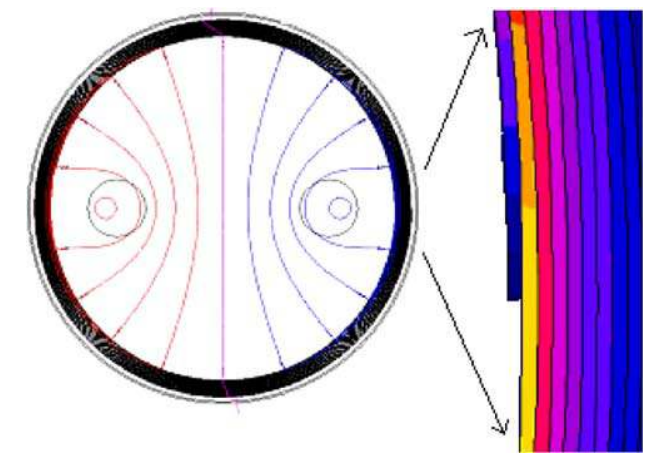

Fig. 3. Spiral effect.

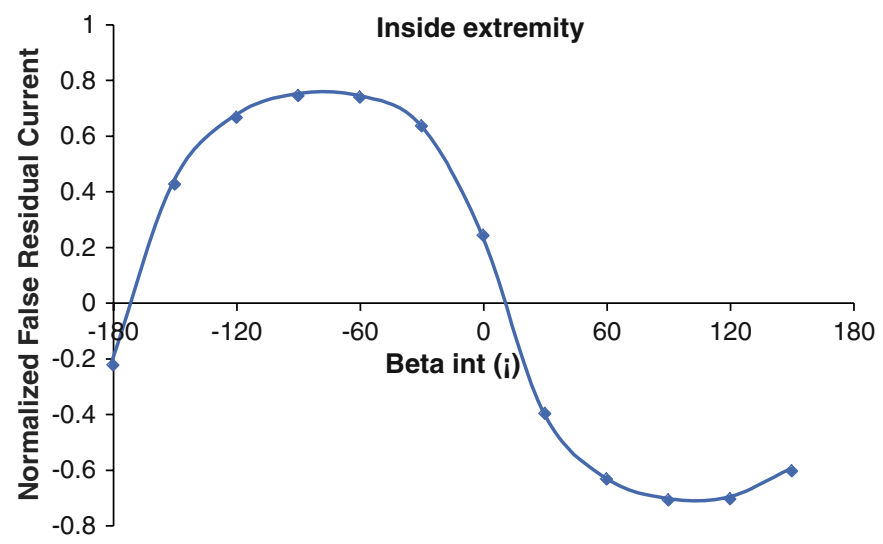

Fig. 4. Influence of angular position on FRCs: inside extremity. The FRC is normalized to $30 \mathrm{~mA}$.

represent the FRC as a function of $\beta_{\text {int }}$ and $\beta_{\text {ext }}$, with, respectively, $\beta_{\text {ext }}=0$ and $\beta_{\text {int }}=0$.

It shows that an optimum configuration of the cores exists that minimizes the FRCs. However, this is not valid for a three phase device because of the rotating magnetic field.

The shielding effect of the internal layers saturates the material. This phenomenon amplifies the effects of primary conductors eccentricity. Under normal conditions, the core and the conductors are centered. Thus, the core saturation is perfectly symmetrical (not considering spiral shape effect). If any eccentricity exists (Fig. 6), the flux is distributed asymmetrically in the two halves of the core. The shielding effect enhances this unbalance.

This effect not only depends on the layer thickness and conductor eccentricity but also on the primary current level (non-linear phenomena). To separate this effect from that of the spiral shape, simulations were conducted on a concentric ring core.

Fig. 7 presents, for $0,0.6$ and $1 \mathrm{~mm}$ eccentricity, a comparison between the normalized FRC with a spiral or a concentric layers ring core as a function of the normalized primary current. For a given eccentricity the difference between the two curves corresponds exactly to the spiral effect. This confirms that the tape ends and the shielding effects are additive. 


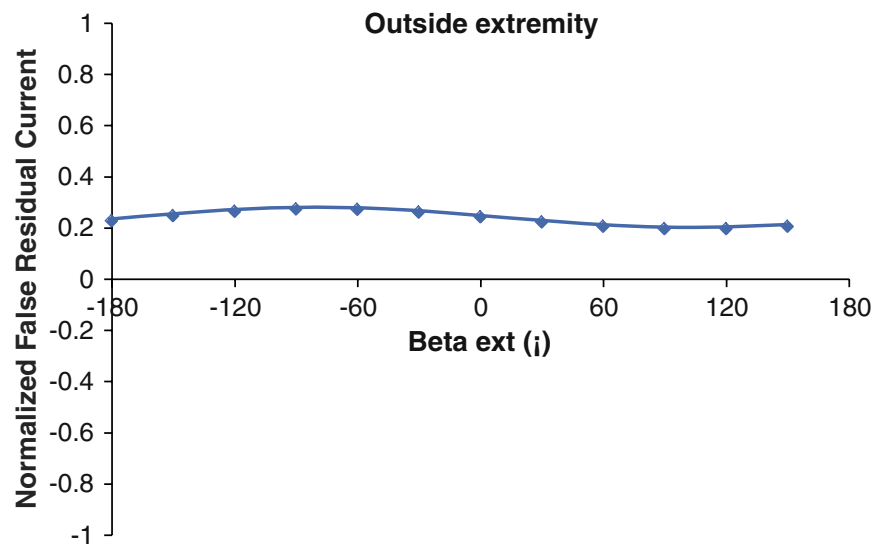

Fig. 5. Influence of angular position on FRCs: outside extremity.

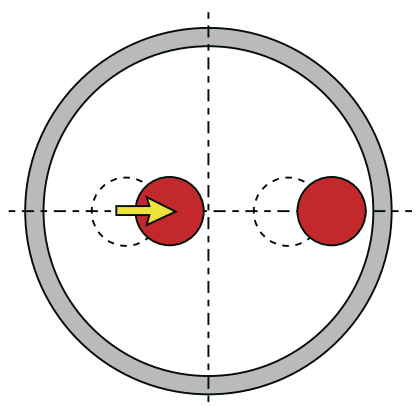

Fig. 6. Conductors eccentricity.

The shielding effect increases highly the circuit breaker sensitivity to the conductor eccentricity. At low current level (less than two times the nominal current) the spiral shape effects are preponderant whereas for high currents, dominates the shielding effect, even with a small eccentricity.

\section{Conclusion and future developments}

The FRCs are a serious nuisance tripping source for the residual current circuit breakers. The magnetic and geometric anomalies can cause the asymmetry in the flux distribution within the core.

Using the finite element simulations, it has been shown that the ring core was particularly sensitive to primary conductor eccentricity. The two-dimensional simulation

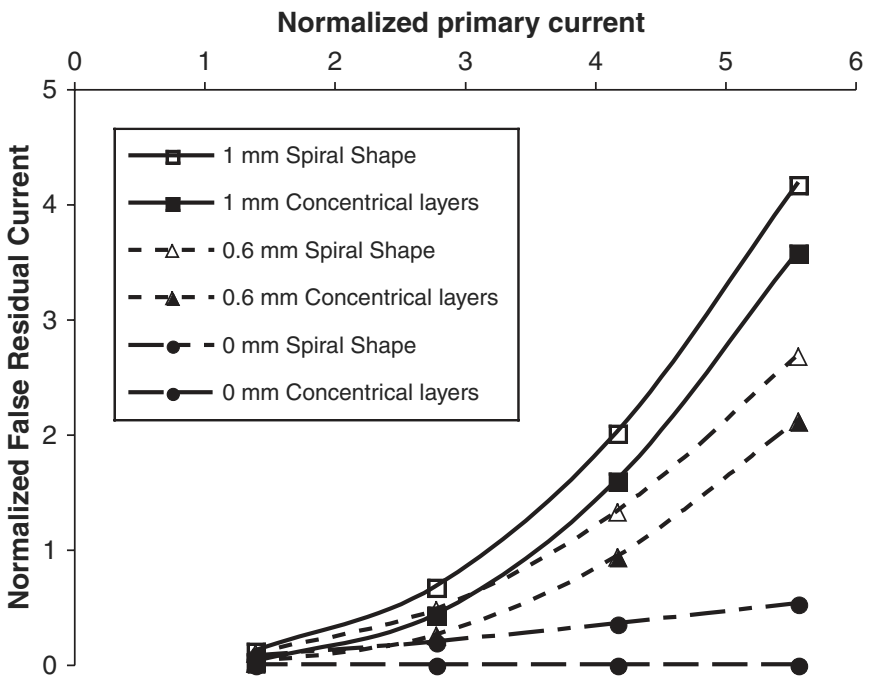

Fig. 7. Comparison concentric/spiral models for a given eccentricity.

allowed different FRCs to be sorted but could not give a precise estimation of the real FRC levels. A threedimensional analysis is necessary to complete this numerical study.

The previous results make necessary to take into account the internal shielding in any new model of a magnetic ring core. Unfortunately, the finite element simulation and modelling of the spiral shape and internal layers is very time and memory consuming. Thus, the work today is focused on a new modelling of the wound magnetic cores by a bulk model considering an apparent anisotropy in $B(H)$ law.

An elliptic permeability model could be a simple an convenient way to achieve this [3].

It is an important step to employ the three-dimensional simulations which will allow the edge effects to be taken into account and therefore should be more realistic.

\section{References}

[1] IEC Standard 947-2.

[2] M.S. Zhou, FR Patent 2799 840, 1999.

[3] J.M. Dedulle, G. Meunier, A. Foggia, J.C. Sabonnadiere, D. Shen, IEEE Trans. Magn. 26 (2) (1990). 